\title{
Evaluation of sapodilla fruit quality using near-infrared spectroscopy
}

\author{
Kusumiyati ${ }^{1 *}$, Syariful Mubarok ${ }^{1}$, Jajang Sauman Hamdani ${ }^{1}$, Farida ${ }^{1}$, Wawan Sutari ${ }^{1}$, Yuda Hadiwijaya ${ }^{2}$, \\ Ine Elisa Putri ${ }^{2}$ and Tino Mutiarawati ${ }^{1}$ \\ ${ }^{1}$ Lecturer, ${ }^{2}$ Alumni of Agrotechnology Studies Program, Agriculture Faculty, Padjadjaran University, Jl. Raya Jatinangor \\ km 21 Bandung, West Java, Indonesia-45363.*e-mail: kusumiyati@unpad.ac.id,kusumiyati@yahoo.com
}

Received 8 September 2017, accepted 20 December 2017.

\begin{abstract}
Fruit quality detection using near-infrared spectroscopy is a fast, accurate, and non-destructive method. Hence the fruits can still be marketed after the measurement. The purpose of this study was to analyze the quality of sapodilla fruit using near-infrared spectroscopy. The study was conducted in March to August 2017 at the Plant Production Technology Laboratory of Horticulture Division, Agriculture Faculty of Padjadjaran University, Jatinangor. The method used in this study was multivariate data analysis of chemometrics. The spectra data were obtained using portable nearinfrared spectrometer (NirVana AG410, Integrated Spectronics Pty, Ltd, Australia) with wavelength range of $312-1050$ nm. Calibration and prediction models were acquired using partial least square (PLS). The results revealed that non-destructive method using near-infrared spectrometer was able to measure sapodilla fruit quality such as, firmness, total dissolved solids, and color values including $L^{*}, a^{*}, b^{*}, h^{\circ}, a^{*} C^{*}$.
\end{abstract}

Key words: Calibration, prediction, root mean square errors of calibration, sapodilla.

\section{Introduction}

Sapodilla (Achras zapota L.) is a long-lived tree native to tropical America. It was introduced to the country of Philippines by Spanish. Nowadays, it spreads through some Asian countries especially Southeast Asia and India, moreover now it is found growing throughout warm areas over the world.

Postharvest researchers and producers describe the quality of fruits by certain characteristics such as sugar content, firmness and color ${ }^{24}$. In general, quality assessment of fruit can be performed by visual assessment, tasting the fruit itself or destructive analysis at the laboratory. Visual assessment will not be able to assess the internal quality, while tasting fruit itself and destructive analysis will damage the fruit. Destructive analysis also requires some hazardous chemicals. Hence, this method is calculated to be cost and time-consuming, also requiring materials and laboratory analysis $^{10,21}$.

Near-infrared spectroscopy has been used to predict fruit quality since $1990 \mathrm{~s}^{12}$. This is an alternative technique that saves time and labor. Near-infrared spectroscopy method can be used to measure the quality of fresh commodities quickly, accurately and environmental friendly ${ }^{3}$. Near-infrared spectrometer record spectra data consists of physical and chemical information from irradiated samples such as total dissolved solids (TDS), firmness, and internal defects ${ }^{19,26}$. There has been a lot of researches done to predict fruit quality using near-infrared spectroscopy as performed in prune fruit ${ }^{25}$, mango ${ }^{23}$, fuji apple ${ }^{17}$, apricot ${ }^{7}$, apple ${ }^{4,18}$ and jujube ${ }^{27}$, 28. This method was also used to detect some fruit-vegetable commodities such as tomato ${ }^{13,14}$ and bitter gourd ${ }^{15}$. Therefore, this work aimed to analyze total dissolved solids (TDS), firmness, and fruit color of sapodilla fruit using near-infrared spectroscopy.

\section{Materials and Methods}

Sample collection: Samples of 300 sapodillas cv. Sukatali were all harvested from the orchard, located in Situraja, Sumedang with the same criteria 90 days after flowering. Then, the fruits were brought to the laboratory for further analysis.

Spectra data acquirement: Six separate measurements using the NirVana AG410 spectrometer with wavelength range of 312-1050 nm were taken out of each sapodilla at six point's scaterred along the axial region, with three points located on each side of the fruit (Fig.1). Hence, the total spectral data was 1800 which then be picked for calibration and prediction set. The spectral data were obtained by positioning the near-infrared spectrometer directly on the fruit skin.

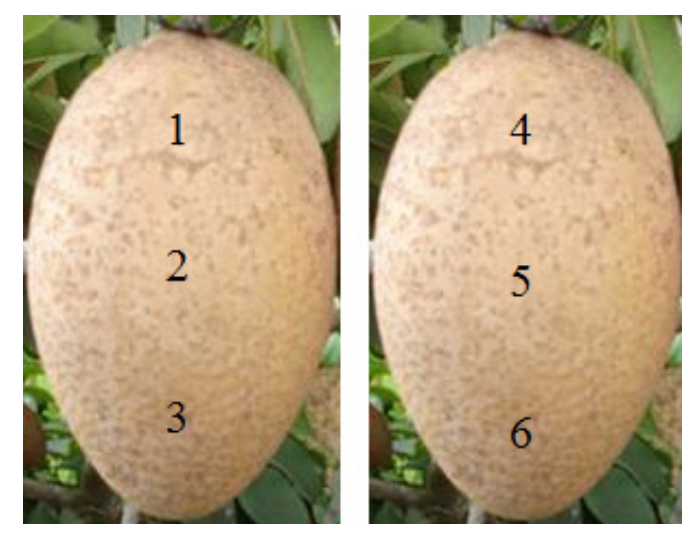

Figure 1. Irradiated points on each side by near-infrared spectrometer. 
Effective calibration model was defined by the correlation coefficient $\left(\mathrm{R}_{\mathrm{cal}}\right)$ between predicted and measured values of each observation and root mean square errors of prediction. The effective models were defined by $\mathrm{R}_{\text {cal }}$ of 0.71 or higher showing rough screening ability, and are preferable for further prediction ${ }^{31}$. Then, the effective calibration models were used to predict the values of another sapodilla fruits (prediction set) in order to test their prediction feasibility. Each model was evaluated according to its accomplishment and prediction accuracy by using the $\mathrm{R}$ between values of predicted model and values of measured values $\left(\mathrm{R}_{\mathrm{pre}}\right)$.

Root mean square error of calibration (RMSEC) is the difference in values between predicted value calibration and reference value of calibration set. Root mean square error of prediction (RMSEP) is the difference in values between predicted value prediction and reference value of prediction set.The calculations of RMSEC and RMSEP are described in the following equations ${ }^{32}$ :

$$
\begin{aligned}
& \text { RMSEC }=\sqrt{\frac{1}{\mathrm{n}_{\mathrm{c}}} \sum_{i=1}^{n^{c}}(\hat{y} i-y i)^{2}} \\
& \mathrm{RMSEP}=\sqrt{\frac{1}{\mathrm{n}_{\mathrm{p}}} \sum_{i=1}^{n^{p}}(\hat{y} i-y i)^{2}}
\end{aligned}
$$

where $\hat{\mathrm{y}} i=$ predicted value of the $\mathrm{i}$ observation, $y i=$ measured value of the $\mathrm{i}$ observation, $\mathrm{n}^{\mathrm{c}}=$ number of observations in the calibration set, $\mathrm{n}^{\mathrm{p}}=$ number of observations in the prediction set.

Effective model should provide a high correlation coefficient of calibration $\left(\mathrm{R}_{\text {cal }}\right)$ and coefficient of determination $\left(\mathrm{R}^{2}\right)$ of prediction and low values of RMSEC and RMSEP, nevertheless both root mean square errors either calibration or prediction should not have a high degree of difference from each other ${ }^{21}$.

The RPD is the relationship between standard deviation (SD) of reference data using destructive method to the standard error (SE) in the prediction set ${ }^{30}$. RPD was originally used to assess how well the calibration model was built between the reference value and the predicted value of NIR ${ }^{29}$. RPD value higher than 3 can be used for screening, while RPD values over than 5 are useful for quality control and RPD values greater than 8 are useful for any application ${ }^{1}$. RPD can be used to assess NIR's ability to predict soil properties ${ }^{6}$. The RPD was classified into 3 categories: category A: RPD > 2.0, category B: RPD $1.4-2.0$, category C: RPD $<$ 1.4. RPD is defined in the following equation:

$$
\mathrm{RPD}=\frac{S D}{S E}
$$

Measurement of firmness: Fruit firmness was determined by using a digital tension gauge (AD-4932A-50N, Taiwan) with measurement range from 0.0 to $50.0 \mathrm{~N}$. Measurement was done by puncturing the fruit at one time. The results were expressed as $\mathrm{N}$ (Newton).

Measurement of total dissolved solids: Total dissolved solids were determined with a digital refractometer model PR-101 $\alpha$ (alpha) (Atago, Model 41325, Japan) with measurement range from 0.0 to $45.0 \%$ Brix. Measurements were obtained using sapodilla fruit extract. The results were expressed as \%Brix.

Color measurement: Color is the basis for sorting many products into commercial grades, but concentration of pigments or other specific constituents might provide a better quality index ${ }^{16}$. Color parameters relate directly to consumer assessment of appearance, pigment concentrations are usually more related to maturity levels, and the concentrations of other certain constituent are related to flavour. The color of the object can be illustrated by several color coordinate systems $8,9,11,20$. The most common used notations is the CIE L* $a^{*} b^{*}$ color space (Fig. 2) designed in 1976 to afford more color differences in relation to human perception of color.

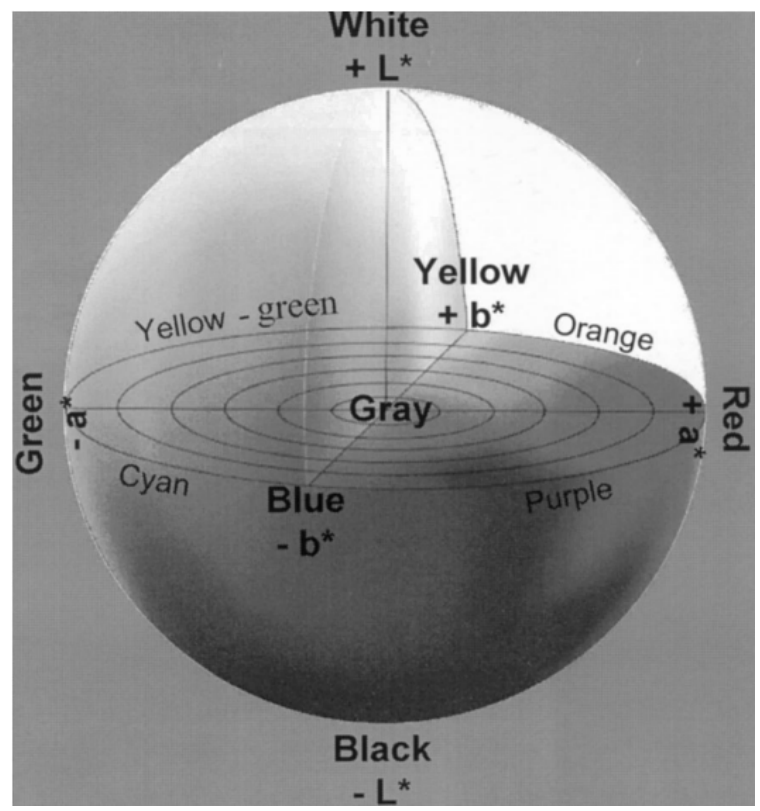

Figure 2. CIE $\mathrm{L}^{*} \mathrm{a}^{*} \mathrm{~b}^{*}$ color space ${ }^{22}$.

Color is measured in common by chromameters to acquire the value of $L^{*}, a^{*}$ and $b^{*}$ in which the sensors are filtered to respond identically to the human eye. $\mathrm{L}^{*}$ value defines the brightness of the color, where 0 is for black and 100 white. $a^{*}$ value denotes the type of green - red, where negative $\mathrm{a}^{*}$ is green, and positive $\mathrm{a}^{*}$ is a red color. The $b^{*}$ describe the blue-yellow type, and the negative $b^{*}$ is blue, whereas the positive $b^{*}$ is yellow. Fruit color measurements were carried out from two different sides of the fruit, whereas in each side measured at the top, middle and bottom of the sapodilla fruit. The upper part is the part affixed to the stem of the fruit.

Hue is location around the circumference of circle and chroma is the gap from center. The calculations of Hue $\left(\mathrm{h}^{0}\right)$ and Chroma $\left(\mathrm{C}^{*}\right)$ are defined in the following equations :

$$
\begin{aligned}
& \mathrm{h}^{0}: \operatorname{tg}^{-1}\left(\frac{b^{*}}{a^{*}}\right) \\
& \mathrm{C}^{*}: \sqrt{a^{*^{2}}+b^{*^{2}}}
\end{aligned}
$$

Multiple regression analysis: Regression is a statistical measure to predict the value of a variable in relation to other variables through linear regression equation. Those variables are divided into two types called dependent and independent variable. When the regression model contains only one dependent and one independent variable, this model is called simple linear regression. The simple linear regression equation is as follows ${ }^{22}$ :

$Y=\beta_{0}+\beta_{1} X_{1}$ 
While $\mathrm{Y}$ is dependent variable, $\mathrm{X}$ is independent variable, whereas $\beta_{0}$ is called the regression constant ( $\mathrm{y}$-intercept), $\beta_{1}$ is coefficient regression of variable $\mathrm{X}_{1}$ (slope)

Multiple linear regression is a linear regression involving more than oneindependent variables ${ }^{22}$. The equation of multiple linear regression is as follows:

$Y=\beta_{0}+\beta_{1} X_{1}+\beta_{2} X_{2}+\ldots+\beta_{\mathrm{n}} X_{\mathrm{n}}+\varepsilon$

where $\mathrm{Y}$ is dependent variable, $\mathrm{X}$ is the independent variable, $\beta_{0}$ is called the $\mathrm{y}$-intercept and $\beta_{1,} \beta_{2}, \beta_{\mathrm{n}}$ are called as slopes and $\varepsilon$ is random error.

\section{Results and Discussion}

Destructive data analysis on sapodilla: Measured data of sapodilla using destructive method would be used as reference data for the development of calibration model. The quality parameters were firmness, total dissolved solids (TDS) and color including $\mathrm{L}^{*}, \mathrm{a}^{*}, \mathrm{~b}^{*}, \mathrm{~h}^{0}, \mathrm{C}^{*}$. The success of value prediction of sapodilla quality using near-infrared spectroscopy was determined by the measured data of destructive method. Destructive data of sapodilla in both calibration and prediction set are presented in Table 1 .

Near-infrared data analysis of sapodilla: Data analysis of sapodilla was measured by reflectance and NIR absorbance data using multivariate data analysis with partial least square (PLS). Total samples used were 300 fruits. Each fruit was irradiated by 6 points as illustrated in Fig 1. Therefore, the total spectra data was 1800 which would then be selected for calibration and prediction set. Calibration and prediction models by partial least square (PLS) using near-infrared spectral data of sapodilla fruits are presented in Table 2.

Firmness assessment: In callibration set the firmness assessment used 604 and 600 data for prediction set with wavelength 312
$1050 \mathrm{~nm}$. Correlation coefficient $\left(\mathrm{R}_{\mathrm{cal}}\right)$ for firmness assessment of sapodilla was 0.94 means high (close to 1 ). This showed that the NIR prediction was close to the measured value using destructive method. The calibration and prediction models of firmness using PLS analysis are visualized in Fig. 3.

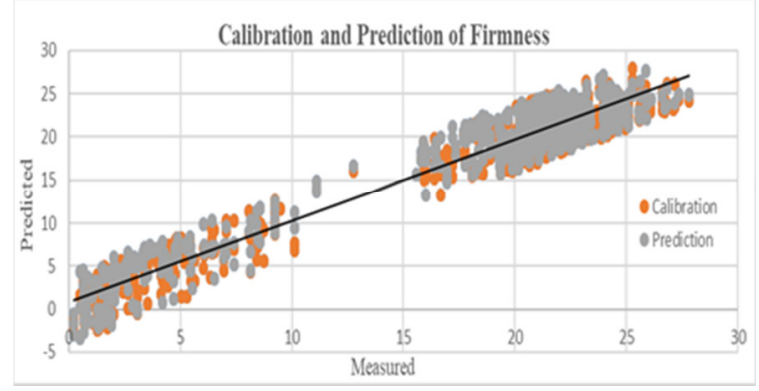

Figure 3.Calibration and prediction models of firmness using PLS analysis.

The root mean square error of calibration (RMSEC) was 1.93. Considering the standard error values in the calibration set, it could be presumed that the calibration model was good due to the error value was close to zero (0). To examine the accuracy of regression equation of calibration set, it is necessary to perform the prediction set.

Prediction set of firmness assessment used different samples and spectra data from the calibration set. The amount data used was 600 both from spectra data and measured data. Correlation coefficient of prediction $\left(\mathrm{R}_{\text {pre }}\right)$ was 0.93 which means the nearinfrared prediction was close to the measured data. RPD value for firmness assessment was 3.94.

The level of accuracy in the prediction set based on calibration modellargely determined by the root mean square errors of prediction (RMSEP). Based on the result of the prediction set, it could be examined that the RMSEP generated was 2.04.

Table 1. Measured data of destructive method in calibration and prediction set of sapodilla fruits.

\begin{tabular}{|c|c|c|c|c|c|c|c|c|}
\hline \multirow{2}{*}{ Parameters } & \multicolumn{4}{|c|}{ Calibration set } & \multicolumn{4}{|c|}{ Prediction set } \\
\hline & $\mathrm{n}$ & Range & Mean & $\begin{array}{l}\text { Standard } \\
\text { deviation }\end{array}$ & $\mathrm{n}$ & Range & Mean & $\begin{array}{l}\text { Standard } \\
\text { deviation }\end{array}$ \\
\hline Firmness (N) & 604 & $0.23-27.81$ & 16.67 & 8.25 & 600 & $0.23-27.81$ & 16.90 & 8.04 \\
\hline TDS (\%Brix) & 606 & $7.5-33.8$ & 22.53 & 4.68 & 605 & $10.5-32.1$ & 22.01 & 4.20 \\
\hline Color $\mathrm{L}^{*}$ & 618 & $31.89-66.53$ & 54.88 & 5.12 & 601 & $37.3-64.01$ & 55.01 & 4.67 \\
\hline$a^{*}$ & 682 & $-3.88-12.72$ & 5.26 & 3.03 & 608 & $-2.25-11.34$ & 5.25 & 2.66 \\
\hline $\mathrm{b}^{*}$ & 687 & $5.96-34.55$ & 23.52 & 5.46 & 630 & $10.22-32.78$ & 23.46 & 5.07 \\
\hline$h^{0}$ & 641 & $47.95-89.80$ & 75.14 & 8.58 & 600 & $56.30-89.47$ & 76.18 & 7.60 \\
\hline $\mathrm{C}^{*}$ & 602 & $8.01-35.01$ & 23.92 & 5.15 & 600 & $12.48-33.34$ & 24.22 & 4.66 \\
\hline
\end{tabular}

Table 2. Calibration and prediction models by partial least square (PLS) using near-infrared spectral data of sapodilla fruits.

\begin{tabular}{|c|c|c|c|c|c|c|c|c|}
\hline \multirow{2}{*}{ Parameters } & & \multirow{2}{*}{$\mathrm{R}_{\mathrm{cal}}$} & \multirow{2}{*}{ RMSEC } & \multirow{2}{*}{$\mathrm{R}_{\mathrm{pre}}$} & \multirow{2}{*}{ RMSEP } & \multirow{2}{*}{ RPD } & \multicolumn{2}{|c|}{ Calibration \& Prediction } \\
\hline & & & & & & & $\mathrm{R}$ & RMSE \\
\hline \multirow{2}{*}{$\begin{array}{l}\text { Firmness } \\
\text { TDS }\end{array}$} & & 0.94 & 1.93 & 0.93 & 2.04 & 3.94 & 0.93 & 1.99 \\
\hline & & 0.85 & 1.66 & 0.78 & 2.05 & 2.04 & 0.81 & 1.88 \\
\hline \multirow{5}{*}{ Color } & $\mathrm{L}^{*}$ & 0.90 & 1.46 & 0.91 & 1.27 & 3.67 & 0.90 & 1.37 \\
\hline & $a^{*}$ & 0.90 & 0.90 & 0.90 & 0.84 & 3.16 & 0.90 & 0.88 \\
\hline & $b^{*}$ & 0.91 & 1.56 & 0.91 & 1.48 & 3.42 & 0.91 & 1.52 \\
\hline & $\mathrm{h}^{0}$ & 0.92 & 2.28 & 0.92 & 2.02 & 3.76 & 0.92 & 2.16 \\
\hline & $\mathrm{C}^{*}$ & 0.91 & 1.47 & 0.90 & 1.33 & 3.50 & 0.91 & 1.40 \\
\hline
\end{tabular}

$\mathrm{R}$-correlation coefficient of calibration; RMSEC-root mean square errors of calibration; $\mathrm{R}$-correlation coefficient of prediction; RMSEP-root mean square error of prediction; RPD-ratio performance to deviation; R-coefficient calibration; RMSE-root mean square errors. 
Total dissolved solids assessment: Calibration set of the TDS assessment used 606 and 605 data for prediction set. Correlation coefficient of calibration $\left(\mathrm{R}_{\text {cal }}\right)$ and prediction $\left(\mathrm{R}_{\text {pre }}\right)$ for TDS assessment of sapodilla were 0.85 and 0.78 , respectively, with the RPD value as 2.04. This result implied that the near-infrared spectroscopy showed the good performance to predict total dissolved solids. The calibration and prediction models of total dissolved solids using PLS analysis are visualized in Fig. 4.

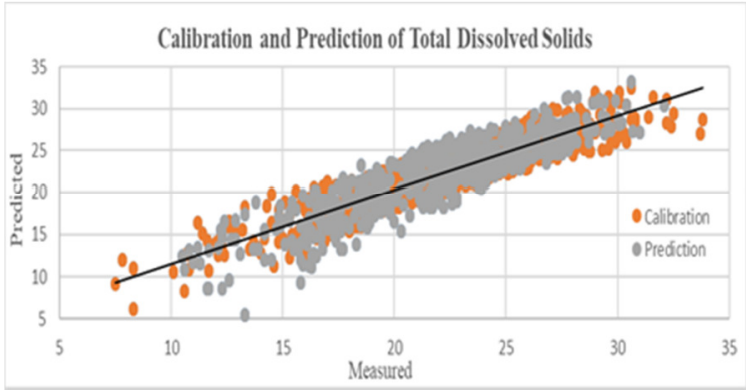

Figure 4. Calibration and prediction models of total dissolved solids using PLS analysis.

RMSEC and RMSEP for both calibration and prediction were 1.66 and 2.05 , respectively. Considering the standard error value in calibration and prediction set, it could be assumed that the calibration and prediction models have been built well because the default error value were close to zero $(0)$.

$L^{*}$ value assessment: The amount of measured and spectra data used for both calibration and prediction set of $L^{*}$ assessment were 618 and 601, respectively with $\mathrm{R}_{\text {cal }}$ as 0.90 and $\mathrm{R}_{\text {pre }}$ as 0.91 which mean close to 1. RMSEC and RMSEP of L* assessment were 1.46 and 1.27 , respectively. RPD value was 3.67 which indicated the good performance of near-infrared prediction. The calibration and prediction models of color including $\mathrm{L}^{*}, \mathrm{a}^{*}, \mathrm{~b}^{*}, \mathrm{~h}^{0}, \mathrm{C}^{*}$ using PLS analysis are visualized in Fig. 5.

$a^{*}$ value assessment: In calibration set the assessment of $\mathrm{a}^{*}$ used 682 and 608 datafor prediction set with wavelength 312-1050 nm which had 0.90 for $\mathrm{R}_{\text {cal }}$ and also 0.90 for $\mathrm{R}_{\text {pre. }}$ The root mean square error of calibration (RMSEC) was 0.90 . Considering the standard error values at the calibration set, it can be assumed that the calibration regression that has been built was acceptable due to the default error value close to zero (0). To analyze the accuracy of regression equation of calibration it is necessary to perform the prediction set.

The level of accuracy in the prediction set based on calibration model largely determined by the root mean square errors of prediction (RMSEP). Based on the result of the prediction set obtained, it can be examined that the root mean square errors prediction (RMSEP) generated was 0.84 .

$b^{*}$ value assessment: Calibration set of the $b^{*}$ assessment used 687 spectra data and 630 for prediction set with wavelength 312 $1050 \mathrm{~nm}$. Correlation coefficient of calibration $\left(\mathrm{R}_{\mathrm{cal}}\right)$ and prediction $\left(\mathrm{R}_{\text {pre }}\right)$ for $\mathrm{b}^{*}$ value assessment were 0.91 and 0.91 , respectively, with the RPD value was 3.42 , which indicated that the near-infrared prediction was sufficiently good for predicting $b^{*}$ value of sapodilla.
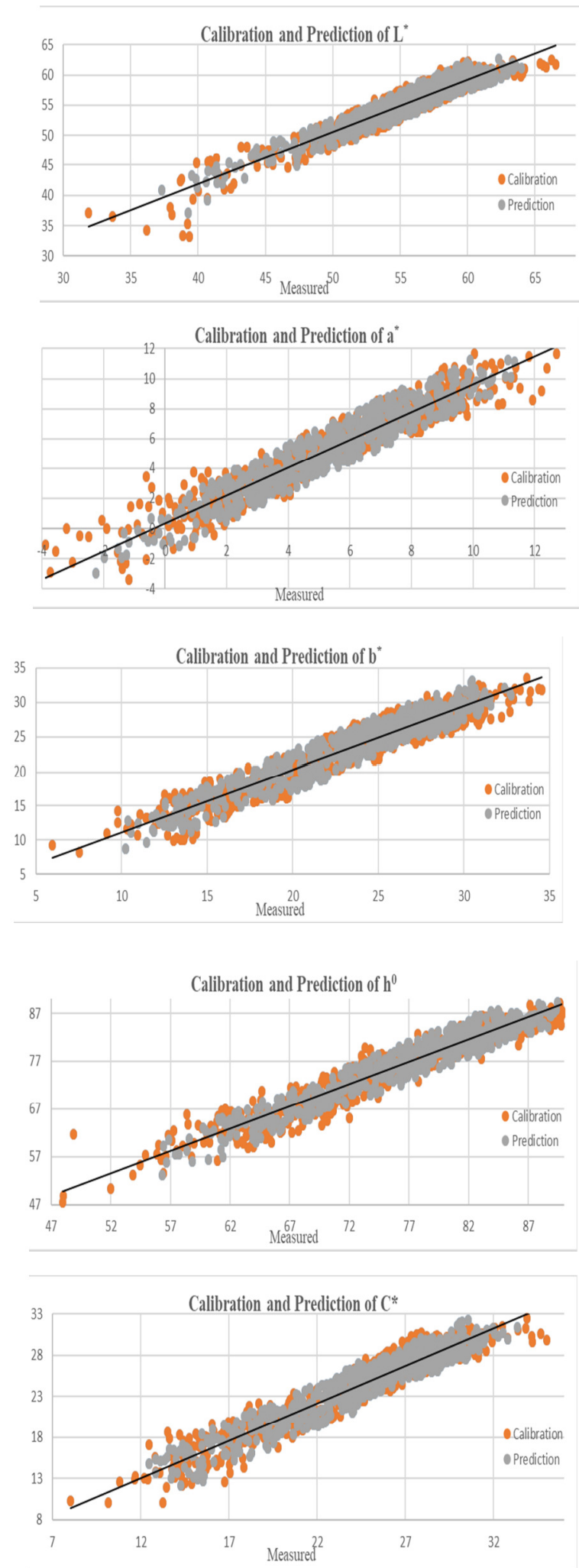

Figure 5. Calibration and prediction models of color including $L^{*}, a^{*}, b^{*}, h^{0}, C^{*}$ using PLS analysis.

In calibration set, the root mean square errors of calibration (RMSEC) was 1.56. The root mean square errors prediction (RMSEP) generated was 1.48. Considering the standard error values in the calibration and prediction set, it can be assumed that the calibration model shave been built well due to the default error close to zero $(0)$. 
Hue value assessment: The number of measured data and spectra data used for calibration and prediction set of $\mathrm{h}^{0}$ assessment were 641 and 600 , respectively. $\mathrm{R}_{\text {cal }}$ and $\mathrm{R}_{\text {pre }}$ of $\mathrm{h}^{0}$ value assessment were 0.92 and 0.92 , respectively, with 3.76 for RPD value which implied the good performance of near-infrared spectroscopy. RMSEC was 2.28 and 2.02 for RMSEP. Considering the RMSEC and RMSEP value, it can be presumed that the calibration and prediction models that have been developed were adequately good due to the default error close to zero (0).

Chroma value assessment: Calibration set of the TDS assessment used 602 and 600data for prediction set. $\mathrm{R}_{\text {cal }}$ and $\mathrm{R}_{\text {pre }}$ for chroma assessment of sapodilla were 0.91 and 0.90 , respectively, with the RPD value as 3.50. This result denoted that the near-infrared spectroscopy showed the good performance to predict Chroma value of sapodilla.

Root means square error of calibration and root means square error of prediction were 1.47 and 1.33 , respectively. Considering the standard error value in calibration and prediction set, it could be assumed that the calibration and prediction models have been built well because the error value were close to zero (0).

\section{Conclusions}

Evaluation of sapodilla quality using near-infrared spectroscopy was able to measure firmness, total dissolved solids and color values with high accuracies and low errors.

\section{References}

${ }^{1}$ Batten, G.D. 1998. Plant analysis using near infrared reflectance spectroscopy: The potential and the limitations. Australian Journal of Experimental Agriculture 38:697-706.

${ }^{2}$ Bellon-Maurel, V. 1992. Application de la spectroscopie proche infrarouge au controle en ligne de la qualite des fruits et legumes. Thesis, ' l'Institut National Polytechnique de Toulouse, France.

${ }^{3}$ Blanco, M. and Villarroya, I. 2002. NIR spectroscopy: a rapid-response analytical tool. Trends Anal. Chem. 21:240-250.

${ }^{4}$ Bobelyn, E., Serban, A., Nicu, M., Lammertyn, J., Nicolaï, B.M. and Saeys, W. 2010. Postharvest quality of apple predicted by NIRspectroscopy: study of the effect of biological variability on spectra and model performance. Postharvest Biol. Technol. 55:133-143.

${ }^{5}$ Butler, W.L. and Norris, K.H. 1963. Lifetime of the long-wavelength chlorophyll fluorescence. Biochim. Biophys. Acta 66:72-77.

${ }^{6}$ Chang, C.-W., Laird, D.A., Mausbach, M.J. and Hurburgh C.R. 2001. Near-infrared reflectance spectroscopy - Principal components regression analyses of soil properties. Soil Science Society of America Journal 65:480-490.

${ }^{7}$ Chen, J.Y., Zhang, H. and Matsunaga, R. 2006. Rapid determination of the main organic acid composition of raw Japanese apricot fruit juices using near-infrared spectroscopy. J. Agric. Food Chem. 54:9652-9657.

${ }^{8}$ Clydesdale, F.M. 1978. Colorimetry-methodology and applications. Crit. Rev. Food Sci. Nutr. 10:243-301.

${ }^{9}$ Francis, F.J. 1980. Color quality evaluation of horticultural crops. HortScience 15:14-15.

${ }^{10}$ Gómez, A.H., He, Y. and Pereira, G. 2006. Non-destructive measurement of acidity, soluble solids and firmness of Satsuma mandarin using Vis/ NIR-spectroscopy techniques. J. Food Eng. 77:313-319.

${ }^{11}$ Hunter, R.S. and Harold, R.W. 1987. The Measurement of Appearance. Wiley-Interscience, New York.

${ }^{12}$ Kawano, S. 1998. New application of nondestructive methods for quality evaluation of fruit and vegetables in Japan. J. Jpn. Soc. Horticult. Sci. 67:1176-1179.

${ }^{13}$ Kusumiyati, Akinaga, T., Yonemori, S., Kawasaki, S. and Tanabe,T.
2007. Evaluation of tomato quality on tree and after harvesting using portable NIR spectroscopy. Journal of the Society of Agricultural Structures, Japan (Nogyo Shisetsu) 38(2):117-126.

${ }^{14}$ Kusumiyati, Akinaga, T., Tanaka, M. and Kawasaki, S. 2008. On tree and after harvesting evaluation of firmness, color, and lycopene content of tomato fruit using portable NIR spectroscopy. Journal of Food, Agriculture and Environment 6(2):132-137.

${ }^{15}$ Kusumiyati, Akinaga, T., Yonemori, S., Shikanai, T., Okamoto, H., Tanabe, T. and Kawasaki, S. 2008. Internal quality sensor of fruit jagged surface: preliminary study of bitter gourd (Momordica charantia Linn). Acta Horticulturae 768:391-398.

${ }^{16}$ Lancaster, J.E., Lister, C.E., Reay, P.F. and Triggs, C.M. 1997. Influence of pigment composition on skin color in a wide range of fruits and vegetables. J. Am. Soc. Hortic. Sci. 122:594-598.

${ }^{17} \mathrm{Liu}$, Y. and Ying, Y. 2005. Use of FT-NIR spectrometry in non-invasive measurements of internal quality of 'Fuji' apples. Postharvest Biol. Technol. 37:65-71.

${ }^{18}$ Liu, Y., Ying, A., Fu, X. and Lu, H. 2007. Experiments on predicting sugar content in apples by FT-NIR Technique. J. Food Eng. 80:986989.

${ }^{19}$ McGlone, V.A., Jordan, R.B. and Martinsen, P.J. 2002. Vis/NIR estimation at harvest of pre- and post-storage quality indices for 'Royal Gala' apple. Postharvest Biol. Technol. 25:135-144.

${ }^{20}$ Minolta 1994. Precise Color Communication. Minolta Co, Ramsey, NJ.

${ }^{21}$ Nicolaï, B.M., Beullens, K., Bobelyn, E., Peirs, A., Saeys, W., Theron, K.I. and Lammertyna, J. 2007. Nondestructive measurement of fruit and vegetable quality by means of NIR spectroscopy: a review. Postharvest Biol. Technol. 46:99-118.

${ }^{22}$ Rawlings, J.O., Pantula, S.G. and Kickey, D.A. 1998. Applied Regression Analysis: A Research Tool. $2^{\text {nd }}$ edn. Springer-Verlag, Inc., New York, US.

${ }^{23}$ Saranwong, S., Sornsrivichai, J. and Kawano, S. 2004. Prediction of ripe-stage eating quality of mango fruit from its harvest quality measured nondestructively by near infrared spectroscopy. Postharvest Biol Technol. 31:137-145.

${ }^{24}$ Shewfelt, R.L. 1999. What is quality? Postharvest Biol. Technol. 15(3): 197-200.

${ }^{25}$ Slaughter, D.C., Thompson, J.F. and Tan, E.F. 2003. Nondestructive determination of total soluble solids in fresh prune using near infrared spectroscopy. Postharvest Biol. Technol. 28:437-444.

${ }^{26}$ Sun, T., Huang, K., Xu, H. and Ying, Y. 2010. Research advances in nondestructive determination of internal quality in watermelon/melon: a review. J. Food Eng. 100:569-577.

${ }^{27}$ Wang, J., Nakano, K. and Ohashi, S. 2011a. Nondestructive evaluation of jujube quality by visible and near-infrared spectroscopy. LWTFood Sci. Technol. 44:1119-1125.

${ }^{28}$ Wang, J., Nakano, K. and Ohashi, S. 2011b. Nondestructive detection of internal insect infestation in jujubes using visible and near-infrared spectroscopy. Postharvest Biol. Technol. 59:272-279.

${ }^{29}$ Williams, P.C. 1987. Variables affecting near-infrared reflectance spectroscopic analysis. In Williams, P. and Norris, K. (eds). NearInfrared Technology in the Agricultural and Food Industries. American Association of Cereal Chemists Inc., Saint Paul, MN, pp. 143-167.

${ }^{30}$ Williams, P. C. and Sobering, D. C. 1993. Comparison of commercial near infrared transmittance and reflectance instruments for analysis of whole grains and seeds. J. Near Infrared Spectrosc. 1:25-32.

${ }^{31}$ Williams, P. 2007. Application to Agricultural and Marine Products. In Ozaki, Y., McClure, W.F. and Christy, A.A. (eds). Near-Infrared Spectroscopy in Food Science and Technology. John Wiley \&Sons, Inc.,New Jersey, pp. 165-218.

${ }^{32}$ Yahaya, O.K.M., MatJafri, M.Z., Aziz, A.A. and Omar, A.F. 2015. Visible spectroscopy calibration transfer model in determining $\mathrm{pH}$ of Sala mangoes. J. Instrum. 10(5):T05002. 